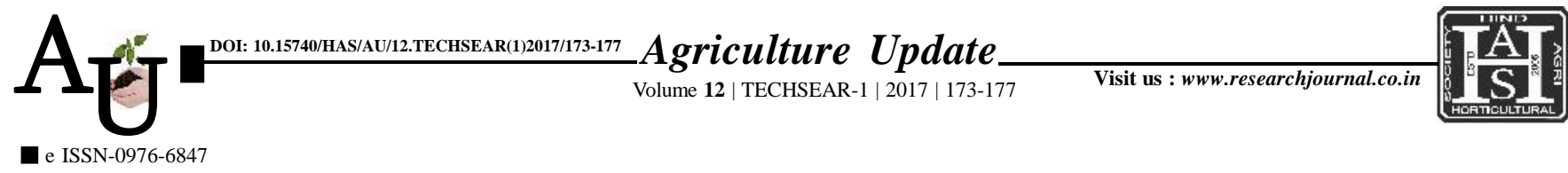

\title{
Research article: Analysis of bioactive constituents from selected genotypes of annatto seed extract through Gc-Ms
}

\section{PRIYANKA, K. KUMARAN AND B. VINOTHINI}

Article Chronicle: Received :

11.07.2017;

Accepted :

26.07.2017

KEY WoRDS:

GC-MS, Carotenoids, Sequiterpenes, Geranylgeraniol, Spathulenol, Anticancerous

Author for correspondence :

\section{PRIYANKA}

Forest College and Research Institute, Tamil Nadu Agricultural University, METTUPALAYAM (T.N.) INDIA

Email:rhinopriya@ gmail.com

See end of the article for authors' affiliations
SUMMARY : The term "annatto" in industrialized countries is commonly referred to Bixaorellana seed extract containing carotenoid-type pigments. In India, it is well distributed in Kerala, Karnataka, Tamil Nadu, Andhra Pradesh, Odisha, West Bengal, Gujarat, Maharashtra, Madhya Pradesh and Chhattisgarh and also reported to be cultivated commercially. The GC-MS results of bixa genotype TNBi -13 and KLBi -3 confirms the presence of 18 compounds and 22 compounds each, respectively.Apart from these compounds some new compounds like Himachol (1.17\%) and Synaptogenin $(1.13 \%)$ were found in bixa genotype TNBi -13 whereas compounds like $\alpha$-Terpinene (1.06\%) and $\alpha$-bulnesene $(0.76 \%)$ were found to be present in bixa genotype KLBi -3.These results suggest that there are chances of variation among the secondary metabolites not only at a quantitative level but also at a qualitative level. Hence profiling of each and every screened genotype is required in order to attain the best selection.

How to cite this article : Priyanka, V., Kumaran, K. and Vinothini, B. (2017). Analysis of bioactive constituents from selected genotypes of annatto seed extract through Gc-Ms. Agric. Update, 12(TECHSEAR-1) : 173-177; DOI: 10.15740/HAS/AU/12.TECHSEAR(1)2017/173-177. 